\title{
Implications of Cellulose in Modeling the Behavior of Vegetal Additive Materials in Clay Based Ceramics: Technical and Archaeological Issues
}

\author{
Ferenc Kristály \\ Additional information is available at the end of the chapter
}

http://dx.doi.org/10.5772/53526

\section{Introduction}

The separate sections are structured so to present novel results of personal experiments and investigations combined with literature references on major domains where cellulose as a model material is involved in clay bricks and archaeometry research. Each section presents a step in materials characterization or testing, which requires the cellulose as model material to decipher the results and observation. Each section may represent a separate step of a chain of investigations, but the information from each is needed to understand the behavior of vegetal materials in clay mixtures, and especially the need for cellulose as a model material.

Working with vegetal waste materials in clay brick industry may seem complex at first. But using the traditional analytical techniques of mineralogy the properties and behavior of different types of vegetal materials may be deciphered. X-ray diffraction reveals that large amounts of vegetal materials components are crystalline (although on a nanometric scale) and are made up by cellulose. This is confirmed by optical microscopy in polarizing light also. Scanning electron microscopy is the best way to characterize the fabric of different vegetal materials. Beyond chemical and physical composition, the fabric - fibre dimensions, orientation and textural porosity - is also a basic property, regarding physical properties of vegetal material grains. Among physical properties is included elasticity, which was observed as main factor in behavior of clay mixtures with vegetal materials regarding deformation at high pressures. Another property of vegetal materials is to form remnants after thermal oxidation. The above mentioned analytical techniques help to demonstrate that these remnants are inorganic, mineral and not char (or carbon based) and that their chemical composition and fabric is characteristic for each vegetal material and plant part. 
The path of remnants formation was followed by thermal analytical techniques and combined sequential firing and optical microscopy techniques. By thermal analysis also the decomposition reactions were determined and evolved gaseous products identified. Here, the role of cellulose was again crucial, since the thermal reactions allow quantification of crystalline and non-crystalline components, if one is aware of characteristic reactions. The heat contribution of vegetal material oxidation was observed to influence the behavior of clay minerals and composition of fired clay products also.

Abbreviations used for investigation techniques: X-ray Powder Diffraction - XPD, Optical Microscopy in Transmitted Polarized Light - OMTPL, Scanning Electron Microscopy - SEM, Energy Dispersive Spectrometry - EDS, Differential Thermal Analysis - DTA, Thermogravimetry - TG, Derivative Thermogravimetry - DTG, Evolved Gas Analysis EGA, VM - vegetal materials.

\section{Cellulose as crystalline component in vegetal materials}

XPD was performed on $<50 \mu \mathrm{m}$ grain size random powder specimens. Samples were obtained by grinding liquid $\mathrm{N}_{2}$ dried materials of sawdust (SD), sunflower seeds hull (SSH) and rice husks (RH). Patterns were obtained in Bragg-Brentano geometry with $\mathrm{Cu}-\mathrm{K} \alpha$ radiation, on top-loaded samples. Patterns were evaluated by Search/Match on ICDD PDF-2 (2005) and the best match was "native cellulose". All patterns display two intense broad peaks at $\sim 15^{\circ}(2 \theta)$ and $\sim 22^{\circ}(2 \theta)$ and a smaller one at $\sim 35^{\circ}(2 \theta)$ (Fig 1). These correspond, in shape and position with data reported by Thygesen et al. (2005). Peak broadening indicates poor crystallinity, $<10 \mathrm{~nm}$ (fiber length), as usually given in literature (Das et al. 2010, Thygesen et al. 2005, Zhao et al. 2007). As in the case of several plant materials (Ververis et al. 2004) the crystalline cellulose content is approximated to be $\sim 20-40 \%$ of the investigated materials. Crystallite sizes (Table 1) were estimated from peak FWHM by the Scherrerformula, structure-less solution, in TOPAS. Instrumental contribution was removed by the Fundamental Parameters Approach peak shape (profile) determination. The amorphous content was modeled by the broad peak method (hump centered at $\sim 28^{\circ} 2 \theta$ ), as the fraction of hump area from the total scattered intensity. However, results are to be treated as semiquantitative, due to intense peak broadening, overlapping and grain size effects.

These crystallite sizes are not directly observed by microscopy techniques. Correction of texture (preferred orientation) and stress-strain effects might be necessary since the individual crystallites usually build up into fibers, rod-shaped quasi crystals. However, for the current applications these aspects might be disregarded and semi-quantitative results are used in the experiments. But, as a main conclusion, crystallinity determination of VM-s from XRD needs combined evaluation techniques and more importantly, combined analytical methods. For instance, cellulose content based on TA gave highest value for SSH, but a clear delimitation from lignin was not possible.

OMTPL of VM grains in $\sim 30 \mu \mathrm{m}$ thin sections revealed a polycrystalline structure. The microscopy observations were conducted with 1 Nicol, crossed Nicols and crossed Nicols with gypsum compensator. The plant fibers in the grains are made up by fibrils, intergrown 
with crystallographic orientation. Sections were obtained in various directions to the fibers. On the SD grains (Fig 2) the fibers are cut perpendicular.

\begin{tabular}{cccccccc}
\hline Position & \multicolumn{3}{c}{ Peak area $\left(\mathrm{cps}^{* \circ}(2 \theta)\right)$} & \multicolumn{3}{c}{ Crystallite sizes $(\mathrm{nm})$} \\
${ }^{\circ}(2 \theta)$ & $(\mathrm{hkl})$ & SD & SSH & RH & SD & SSH & RH \\
\hline$\sim 14.9$ & $?$ & 6.54 & 1.98 & 0.81 & 1.7 & 2.2 & 4.5 \\
$\sim 16.6$ & $(111)$ & 3.84 & 2.23 & 1.91 & 2.1 & 2.6 & 2.6 \\
$\sim 20.6$ & $(021)$ & 1.12 & 4.21 & 4.89 & 6.1 & 3 & 2.1 \\
$\sim 22.3$ & $(002)$ & 20.34 & 10.74 & 13.12 & 3.3 & 3.6 & 2.5 \\
$29.44^{a}$ & $(040)$ & 1.59 & & & 1566 & & 16 \\
$\sim 34.7$ & & 1.48 & 0.84 & 0.70 & 7.4 & 11.9 & 16 \\
\hline Crystalline $\sum_{\text {area }}$ & $\mathrm{cps}$ & 33.32 & 20.00 & 21.43 & area of cellulose peaks \\
Amorphous $\Sigma$ area & $\mathrm{cps}$ & 70 & 53 & 45 & \multicolumn{3}{c}{ area of $\sim 28^{\circ} 2 \theta$ hump } \\
crystallinity & $\%$ & 32 & 24 & 32 & \multicolumn{3}{c}{ relative percents } \\
\hline
\end{tabular}

Table 1. Crystallite sizes for cellulose ( $\mathrm{a}-\mathrm{Ca}$-oxalate or oxalic acid peak)
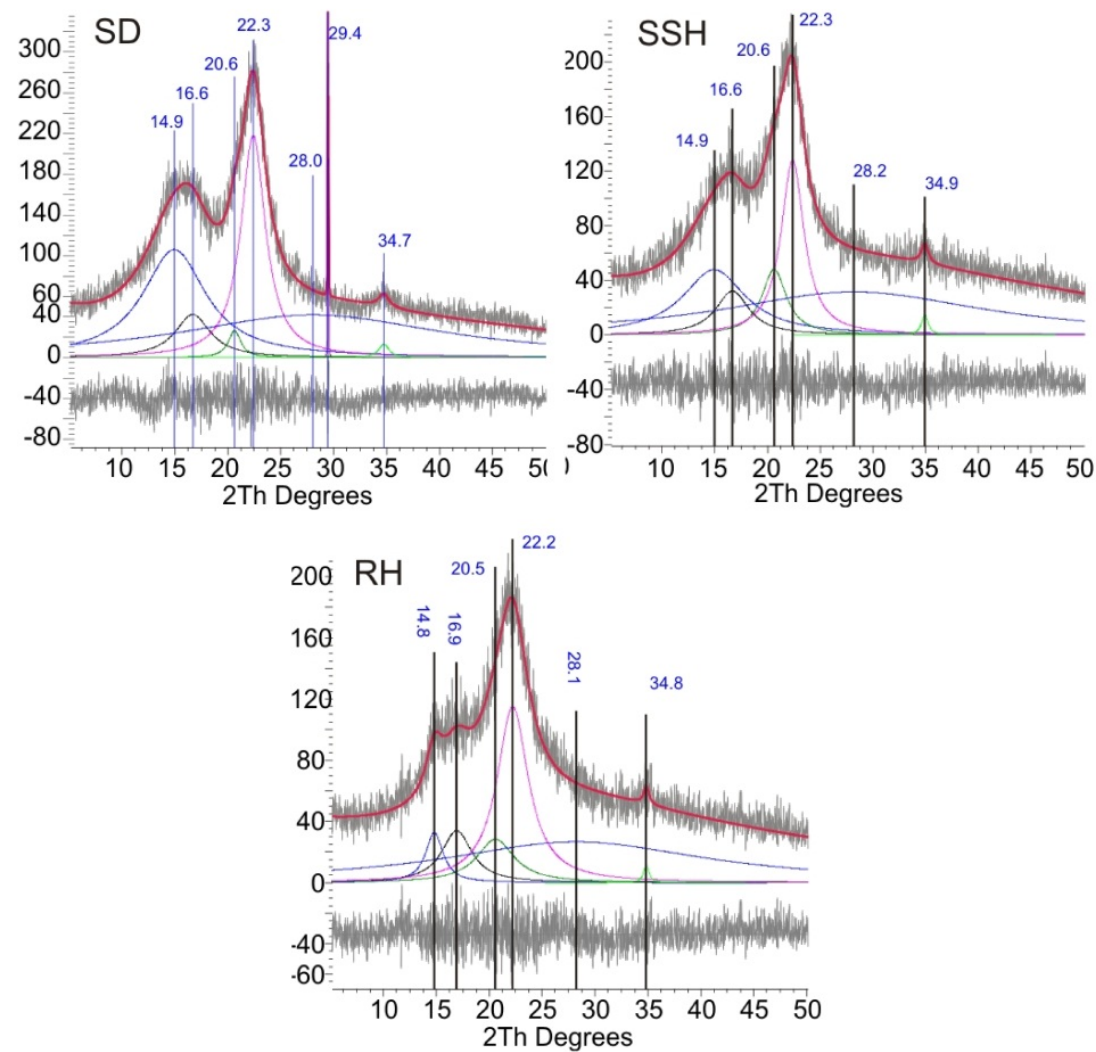

Figure 1. Cellulose peaks and amorphous hump (peak at $\sim 28^{\circ}(2 \mathrm{Th})$ 
1 Nicol
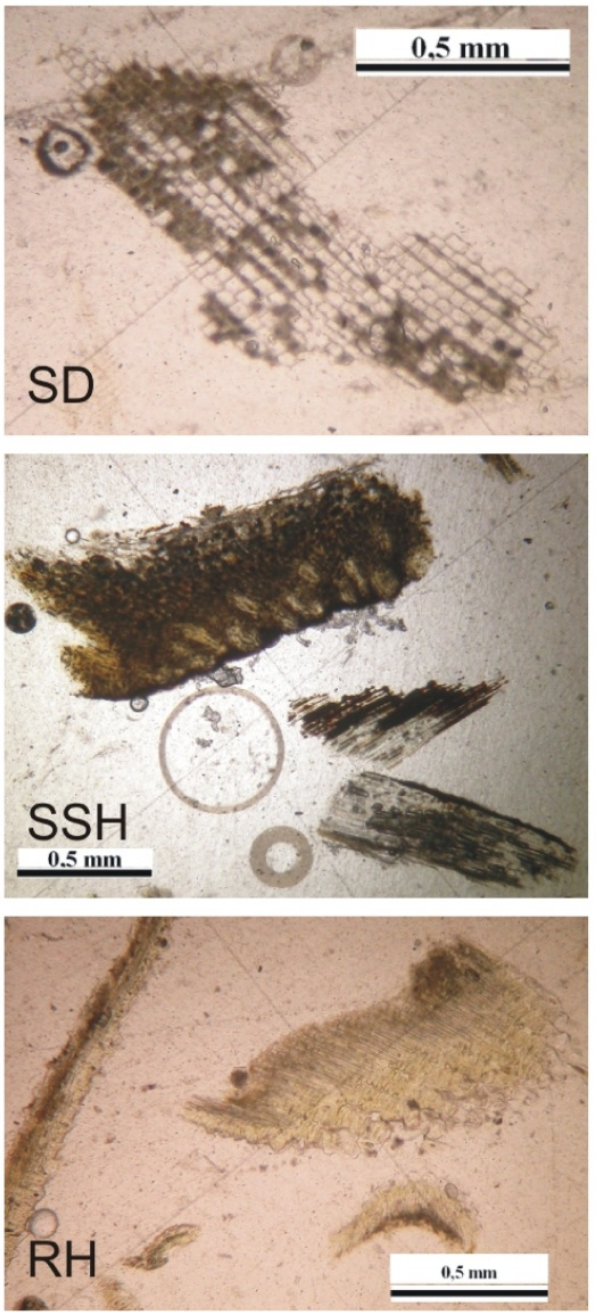

x Nicols ${ }^{+}$g.c.
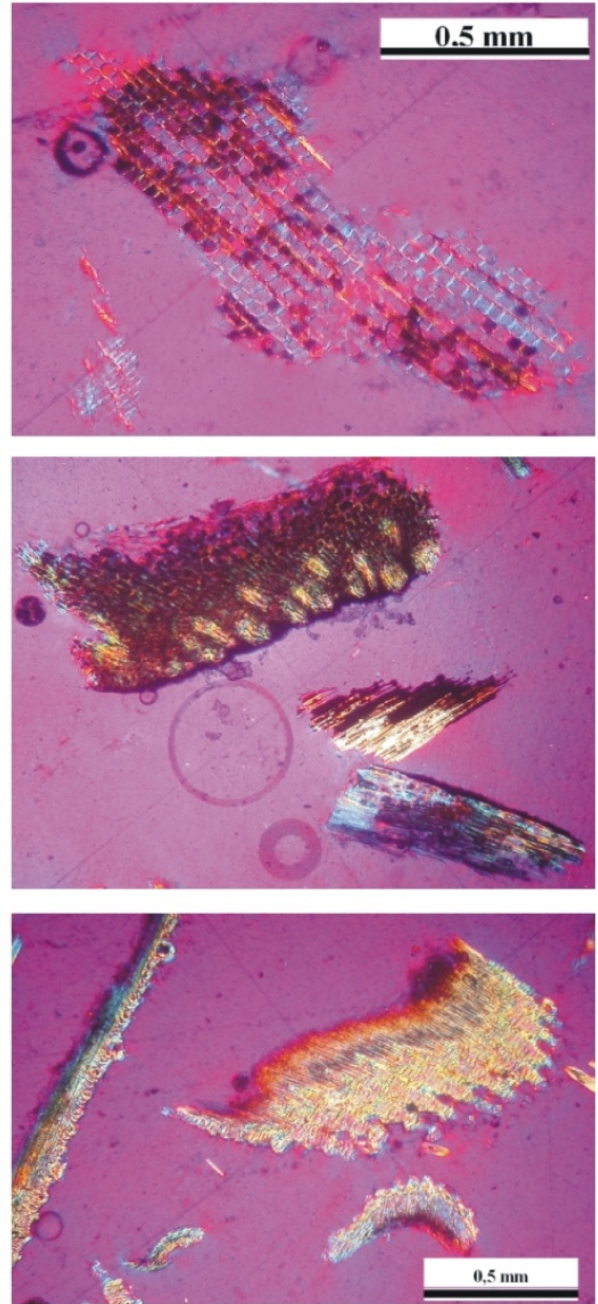

Figure 2. OMTPL images of vegetal grains ( $\mathrm{x}$ Nichols=crossed Nichols, g.c. $=$ gypsum compensator $)$

On the image with crossed Nicols and gypsum compensator, the different crystallographic orientation of fiber groups is observed. For SSH the largest grain shows the section perpendicular to the elongation of the hulls, displaying micrometric bunches of fibrils in similar crystallographic orientations. The fibrils are on the outer, harder part of the hulls. To the inner parts, fibrils disappear and an amorphous material is seen, probably noncrystalline cellulose and lignin. $\mathrm{RH}$ is shown in 3 orientations, the largest grain is oblique to the platy husks, the longest is perpendicular and along the elongation, while the small curved grains are perpendicular to the platy husks and elongation too. As compared to SD and SSH, the smallest fibrils are observed. A layered structure is seen: massive lignin on the 
outer part, long fibrils parallel to elongation and platy-ness in the middle and small fibrils building up the inner undulated surface.

\section{Fabric (microstructure) of vegetal grains, plant-specific features, characteristic chemical elements in the cellulose and lignin}

SEM and EDS on polished surface raw vegetal samples evidenced the chemical elements in the organic compounds and the fine-scale structure of fibers also. For sample preparation methodology and experimental details see Kristály \& Gömze (2008). In the SD grains texture the section perpendicular to the fibers shows the polygonal structure (Fig 3, SD-a) with various dimensions of the individual polygons (Fig 3, SD-b). These in a natural state are empty on the inside and are sections of channels running parallel to the grains elongation (Fig 3, SD-c). Thus, the elongated grains of SD are due to the existence of long fibers in one direction only.
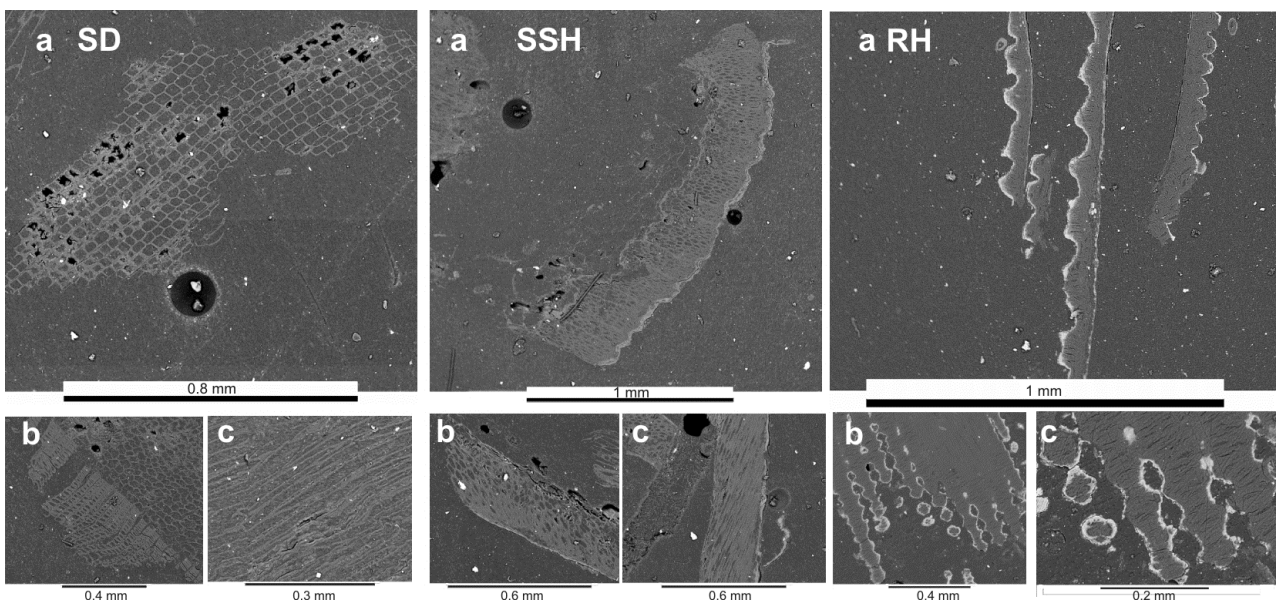

Figure 3. BSE images of vegetal material grains

For SSH grains, the differentiated texture is better observed, the light gray shell is the Kenriched organic material. The section parallel to the hulls elongation (Fig 3, SSH-a) displays a sponge-like structure, covered by the K-rich shell. On detailed oblique sections (Fig 3, SSH-b and c) the micrometric polygonal cavities of the sponge-like structure turn out to be fibers - channels running perpendicular to the elongation and in parallel with the K-rich shell. In RH grains the white strips on one side of the grains (Fig 3, RH-a) are the Si-rich (up to $40 \% \mathrm{Si}$ ) cellulose parts, on the inner side of the husks. Small amount of Si-enrichment is also observed on the outer shell of husks and in the fine-fibrous mass. Perpendicular to the elongation the uneven inner surface is visible. In section parallel with the elongation, the micrometric compact fibers perpendicular to the elongation are seen (Fig 3, RH-c). In the plane of elongation, the Si-rich uneven inner surface forms a hollow reticular planar texture (Fig 3, RH-b and RH-c). This structure may have pillaring role, when the structure is undertaken to mechanical deformations. 
Using the routine SEM and EDS sample preparation and investigations of mineralogy, we could evidence basic features of vegetal materials and important differences in their fabric which determine their behaviour in various conditions/applications.

\section{Thermal decomposition of vegetal materials as cellulose depolymerization, evolved heat and gases, fabric transformation}

Simultaneous DTA, TG and DTG ("derivatography") was performed in order to observe the thermal decomposition reactions of vegetal materials. The most important observations are that 1) all investigated vegetal materials display very similar thermal reactions (Kristály et al. 2010a); 2) the type of reactions depend on the $\mathrm{O}_{2}$ content of reaction media and 3) activation energies and heat of reaction vary depending on the inorganic content of the vegetal materials. The thermal reactions observed on SD, SSH and RH samples are summarized in Table 2 as DTA and DTG peak temperatures. The $2^{\text {nd }}$ reaction is of depolymerization, while the $3^{\text {rd }}$ one is combustion in the $5 \mathrm{mg}$ samples and partial carbonization in the $200 \mathrm{mg}$ samples. We could learn from these reactions that oxidation as decomposition of organic materials occurs only if the amount of investigated materials is low so that $\mathrm{O}_{2}$ content of a static air atmosphere is sufficient. The carbonization of cellulose is supported by the black residue left at $700^{\circ} \mathrm{C}$. The residue for $5 \mathrm{mg}$ samples was white and glassy powder.

\begin{tabular}{|c|c|c|c|c|c|c|c|c|c|c|c|c|}
\hline \multirow[t]{2}{*}{ Nr. } & \multicolumn{2}{|c|}{ SD 5mg } & \multicolumn{2}{|c|}{ SD 200mg } & \multicolumn{2}{|c|}{ SSH 5mg } & \multicolumn{2}{|c|}{ SSH 200mg } & \multicolumn{2}{|c|}{ RH $5 \mathrm{mg}$} & \multicolumn{2}{|c|}{ RH 200mg } \\
\hline & 岕 & $\begin{array}{l}U \\
\text { 号 }\end{array}$ & 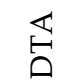 & U. & 岕 & טِّ & 岕 & 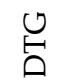 & 㭊 & U. & 岕 & $\begin{array}{l}u \\
\stackrel{0}{0}\end{array}$ \\
\hline 1 & - & - & $120 \downarrow$ & 120 & - & - & 120 & 120 & - & - & $127 \downarrow$ & 130 \\
\hline 2 & $349 \uparrow$ & 336 & $296 \uparrow$ & 290 & $318 \uparrow$ & 290 & $270 \uparrow$ & 280 & $330 \uparrow$ & 306 & $285 \uparrow$ & 285 \\
\hline 3 & $458 \uparrow$ & 464 & $445 \downarrow$ & 352 & $478 \uparrow$ & 500 & $394 \downarrow$ & 330 & $445 \uparrow$ & 445 & $336 \uparrow$ & 338 \\
\hline 4 & & & $450 \downarrow$ & - & & & $445 \downarrow$ & & & & $487 \downarrow$ & - \\
\hline 5 & & & & & & & & & & & $515 \downarrow$ & - \\
\hline
\end{tabular}

Table 2. Peak temperatures of DTA curves on VM, without peak deconvolution.

Deconvolution approach on DTA curves revealed several overlapping peaks, which were determined for $5 \mathrm{mg}$ samples. Deconvolution was performed in Fityk 0.9.4. (Wojdyr 2010) using split-PearsonVII function on DTA curves with base-line correction in WinDer. The base-line shifts after correction are due to the heat diffusion effect of crucibles and loss of sample as related to the constant volume (mass) of inert material. At least 3 major exothermic peaks, followed by at least one endothermic peak are observed (Fig 4). Comparing values from Fig 4 to those of Table 2 the small differences are observed for the peaks observed without deconvolution (for the $5 \mathrm{mg}$ samples). The peak between $2^{\text {nd }}$ and $3^{\text {rd }}$ exothermic shows similar values for SD, SSH and $\mathrm{RH}$, but its intensity varies largely. It represents the oxidation of functional groups liberated by breaking polymer chains. The endothermic peak following oxidation peaks is not a carbonization reaction. It is the 
reorganization into inorganic material of non-volatile (mineral) elements in the VM. This also explains the large differences in the peak $\mathrm{T}\left({ }^{\circ} \mathrm{C}\right)$. Additional reactions are observed on $\mathrm{RH}$, which are assigned to be the $\mathrm{SiO}_{2}$ crystallization - reorganization processes. The large endothermic peak $>700^{\circ} \mathrm{C}$ are instrumental contributions, the asymmetry caused by the almost empty sample crucible vs. the $\alpha-\mathrm{Al}_{2} \mathrm{O}_{3}$ containing crucible. Heat of reaction (Apeak $\left[{ }^{\circ} \mathrm{C}^{2}\right] / \mathrm{M}_{\text {sample }}$ [mg]) is 53.97 for SD, 64.53 for SSH and 31.38 for $\mathrm{RH}$ (where Apeak was taken as the total exothermic peaks). The solid residues were $0.2 \mathrm{mg}$ for SD, 0.6 for SSH and 1.1 for $\mathrm{RH}$.
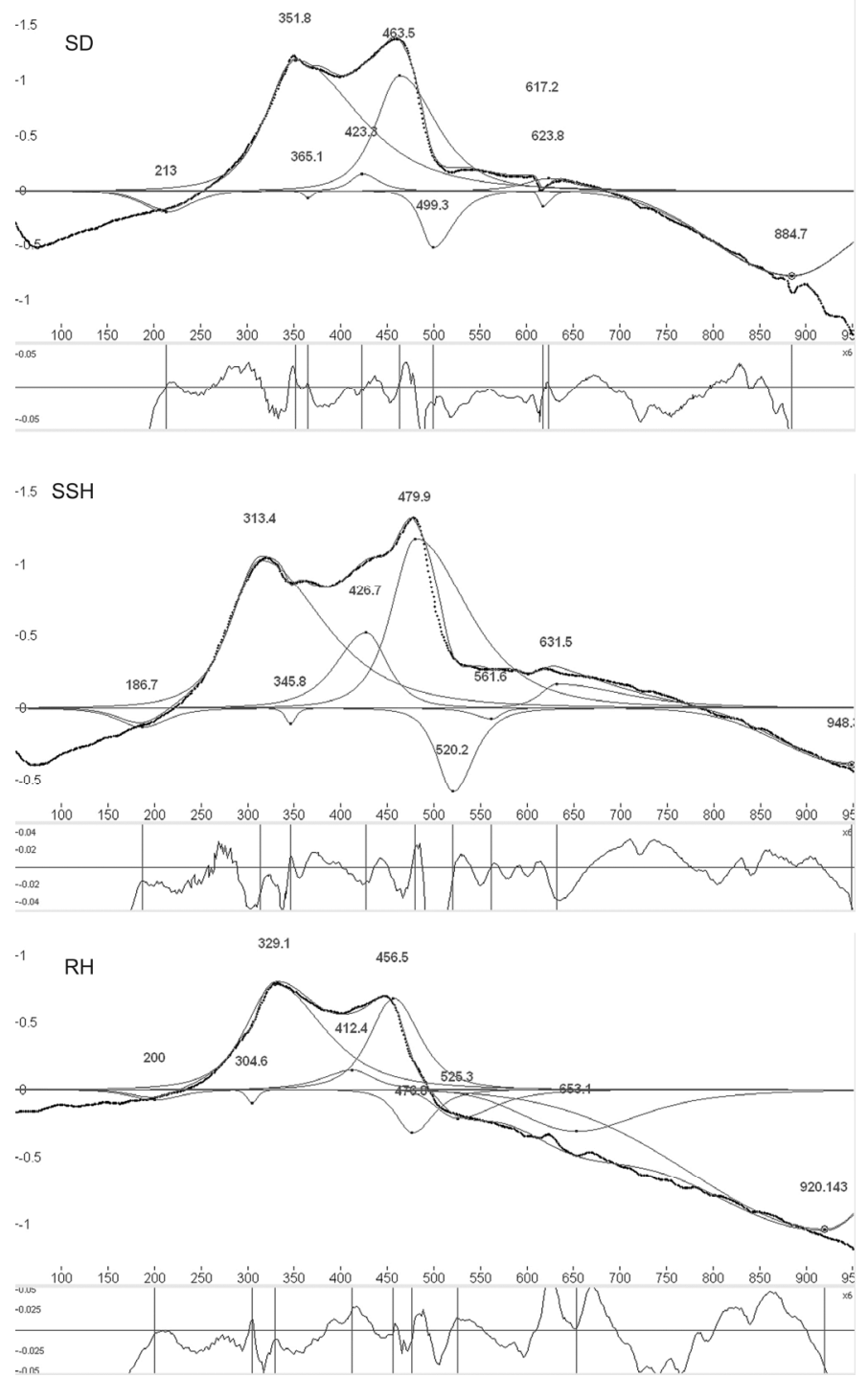

Figure 4. Deconvoluted DTA curves $\left(5 \mathrm{mg}\right.$ sample, $10^{\circ} \mathrm{C} /$ min linear heating) 
EGA by means of quadrupole mass spectrometry (QMS) is a useful tool to observe volatile products for thermal reactions. In our experiments (Kristály et al. 2010) we have used equipment at University of Debrecen (Hungary) (Szöőr \& Bohátka 1985). Simultaneous detection of various atomic/ionic or molecular mass compounds is possible. By evacuating the evolved gases trough a capillary system into a high vacuum drive, the gases from the derivatograph furnace are directly driven to the spectrometer. Thus, static-air atmosphere investigations are possible, on sample amounts ranging from $5 \mathrm{mg}$ to several hundreds of mg-s. Liberation of $\mathrm{H}_{2} \mathrm{O}$ and $\mathrm{OH}^{-}$are observed at similar reactions (Fig 5), indicating that $\mathrm{OH}-$ to- $\mathrm{H}_{2} \mathrm{O}$ reactions support the oxidations. However, in the second intense reaction $\left(3^{\text {rd }}\right.$ among deconvoluted peaks) less (or no) water and more $\mathrm{CO}_{2}$ is produced. This observation supports the depolymerization-to-combustion route of thermal decomposition. The three peak system of decomposition in SSH is also observed in the QMS patterns. The reaction path is supported by data from literature (Table 3), but also the presence of other cellulose like polysaccharides is evidenced.
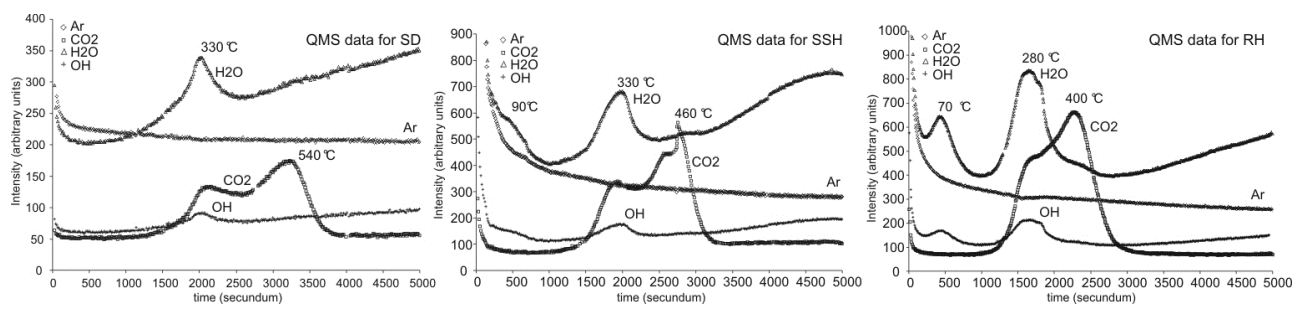

Figure 5. EGA by QMS of VMs (5mg sample, $10^{\circ} \mathrm{C} / \mathrm{min}$, static-air, $500 \mathrm{sec}=83^{\circ} \mathrm{C}$, Ar flushing) (Kristály et al. 2010)

OMTPL of sawdust, rice husks and sunflower seeds hull materials was applied to directly observe changes during a sequential firing experiment. In Fig 6 the first step of the transformations after $250^{\circ} \mathrm{C}$ is exemplified (for comparison with the original material see Fig 2.).

\begin{tabular}{ccccccccc}
\hline \multicolumn{2}{c}{} & Reaction & \multicolumn{3}{c}{ Our results } & Szcześniak & \multicolumn{2}{c}{ H. Yang et.al. (2007) } \\
nr. & type & SD & SSH & RH & et.al. 2008 & ${\text { cell. }{ }^{~}}^{\text {hemic. }^{2}}$ & lign. \\
1 & exothermal & 352 & 314 & 330 & 300 & 270 & 350 & cont. \\
2 & exothermal & 467 & 480 & 457 & 440 & \multicolumn{2}{c}{ no combustion $^{*}$} \\
\hline
\end{tabular}

Table 3. Exothermal peak temperatures, compared to experiments on cellulose and derivatives ( ${ }^{*}$-inert atmosphere)

The images with crossed Nicols and gypsum compensator enabled to observe the vitrification/amorphization of VM textures. SD has preserved most of its crystalline fibrils as evidenced by the variation of interference colors upon specimen rotation. SSH already presents some degree of amorphization as black spots in the fibrillar fabric, and some degree of shrinkage is observed, as gap between clay matrix and SSH grains. $\mathrm{RH}$ was undertaken to total amorphization, indicating that $\mathrm{H}_{2} \mathrm{O}$ liberated is part of the $\mathrm{Si}$ - cellulose polymer and 
individual crystallites are below detection limit of OMTPL. This fact is also sustained by the brownish dark color of the vegetal mass, which at higher temperatures is cleared and transformed to glass. At $450^{\circ} \mathrm{C}$ (Fig 7) the total combustion of organic components is observed without shrinkage of SD and $\mathrm{RH}$ grains and $\sim 70 \%$ by volume shrinkage of $\mathrm{SSH}$ grains.
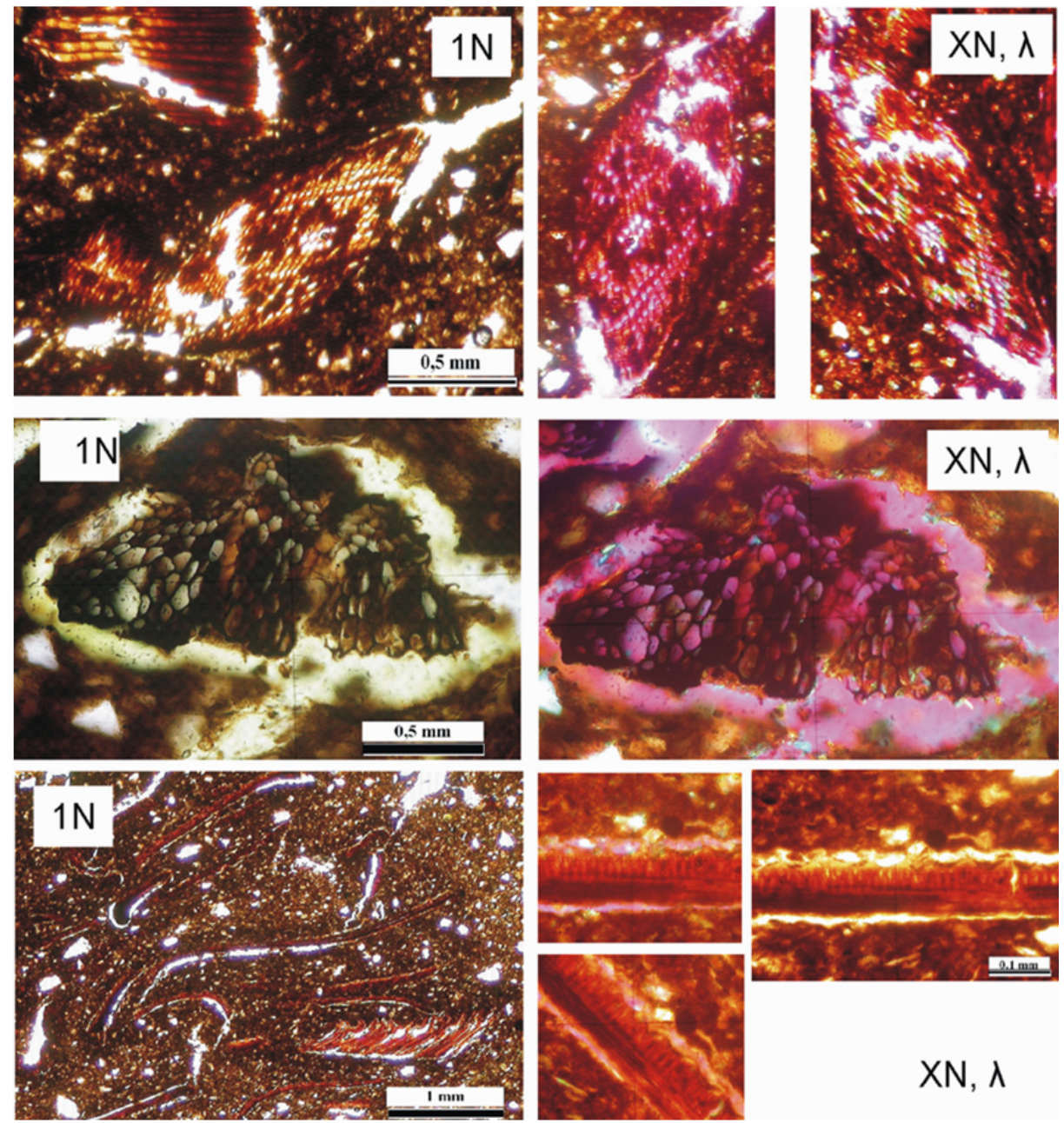

Figure 6. OMTPL images of $\mathrm{VM}$ at $250^{\circ} \mathrm{C}$ 

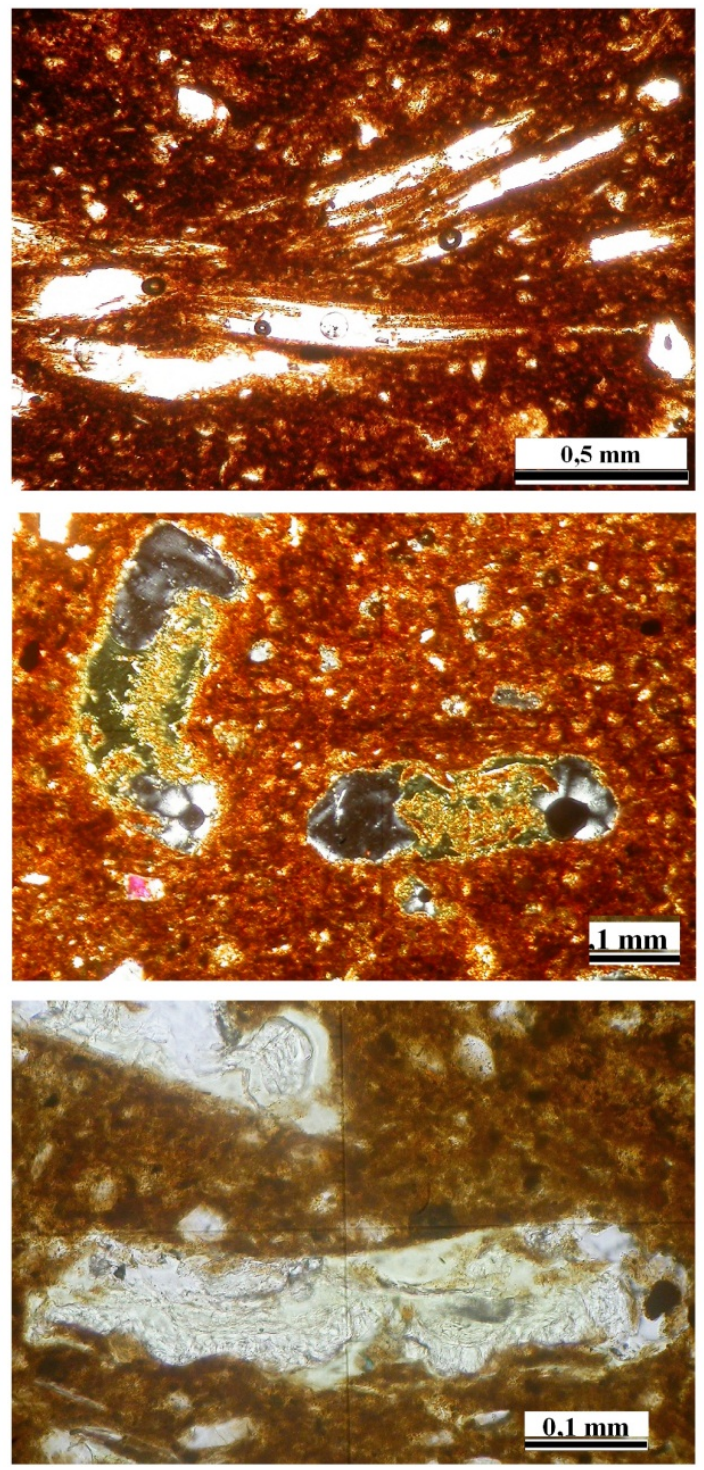

Figure 7. VM remnants at $450^{\circ} \mathrm{C}$ (top-SD, $1 \mathrm{~N}$; centre-SSH, $\mathrm{xN}$; bottom-RH, $1 \mathrm{~N}$ )

In comparison with the TA results, the second exothermic peak continues above this temperature due to the diffusion of heat in the clay material and sample holder crucible. The characterization of remnants in sequential firing experiments is made difficult trough the thin specimen preparation from metastable materials. This step of experiment leads eventually to further necessary investigations to understand what the products are and how they influence the properties and composition of the materials they are admixed in. 


\section{Solid-state remnants of thermally decomposed vegetal materials}

As indicated by TG results, vegetal materials do not decompose totally to volatile compounds. The solid-state remnants are the oxidized form of alkalis, alkaline earths, metals and semimetals contained in the organic compounds (or as biominerals e.g. Caoxalate crystals). These materials must be differentiated from the char and ash type remnants, which form due to incomplete combustion of organic matter. As evidenced by $\mathrm{XRD}$ the remnants are different for each vegetal material.

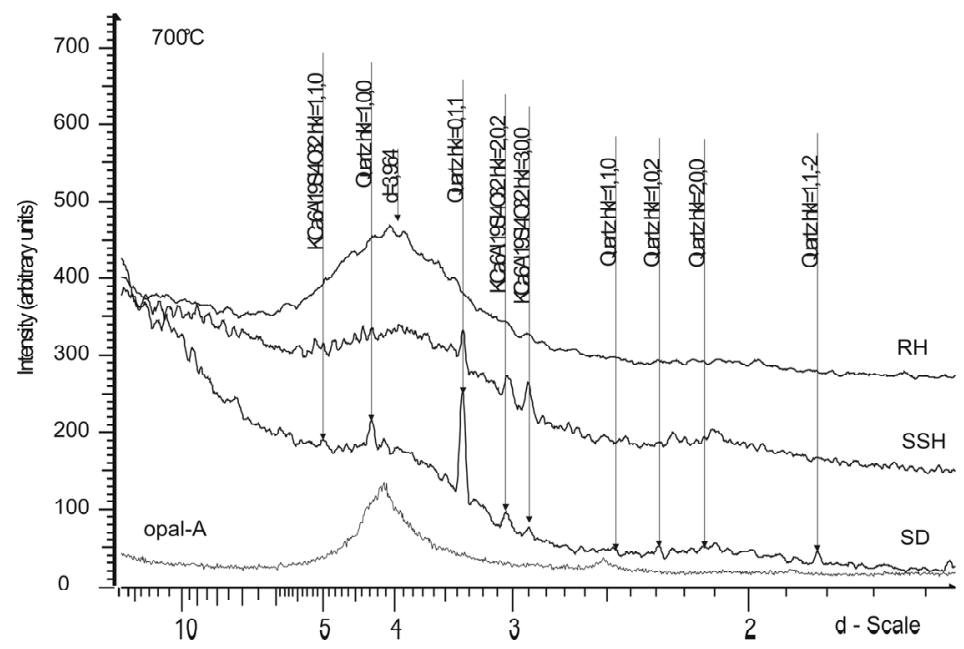

Figure 8. XRD patterns of VM remnants (smoothed, with original background, Y-scale translated)

Amorphous silica (perhaps nano-crystalline cristobalite) remains from $\mathrm{RH}$, while SD and SSH remnants are more complex, with crystalline components too (Fig 8). For comparison, an opal XRD pattern is also shown. The most crystalline material as related to the amorphous hump is observed in the SD remnants and quartz is the dominant crystalline component. The SSH produces mainly silicates of $\mathrm{Na}, \mathrm{Mg}$ and $\mathrm{Ca}$ with $\mathrm{K}$ as main cation, explained by the original chemistry of $\mathrm{SSH}$ grains. $\mathrm{RH}$ produced only amorphous $\mathrm{SiO}_{2}$ as expected. In special treatment procedures, cristobalite and tridymite can be obtained from rice husks ash (Abou-Sekkina et al. 2010).

OMTPL investigations on materials fired at $900^{\circ} \mathrm{C}$ revealed the final state of remnants (Kristály \& Gömze 2008), since the recrystallized matrix offered a good enough mechanical protection for remnants in the pores. Basically, the fabric observed in raw state is observed for SD, SSH displays the shrinkage affected material while RH has the hollow glassy network formed.

SEM on remnant materials was performed to observe their morphology. Peculiar details were revealed which enable us to link together the raw composition, thermal behavior and mechanical properties of VM (Fig 10). 


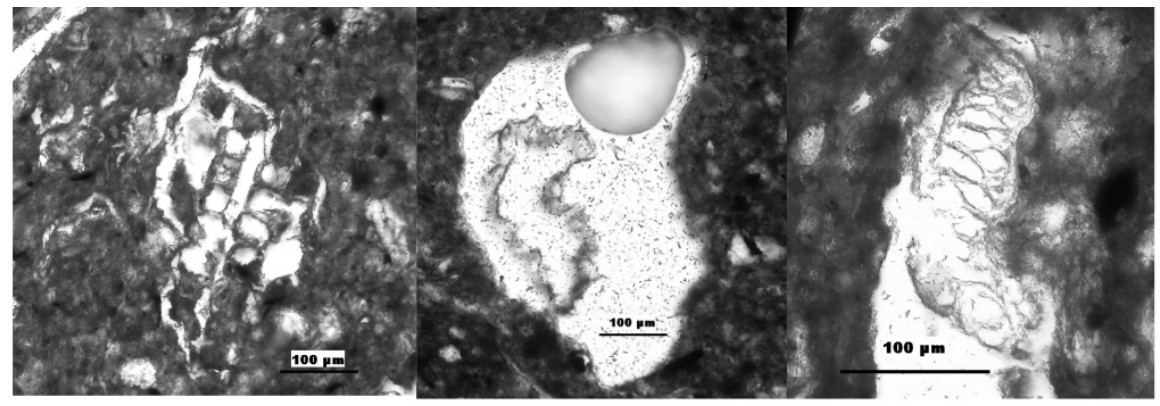

Figure 9. OMTPL images of VM remnants is thin section (left SD, center SSH, right RH).
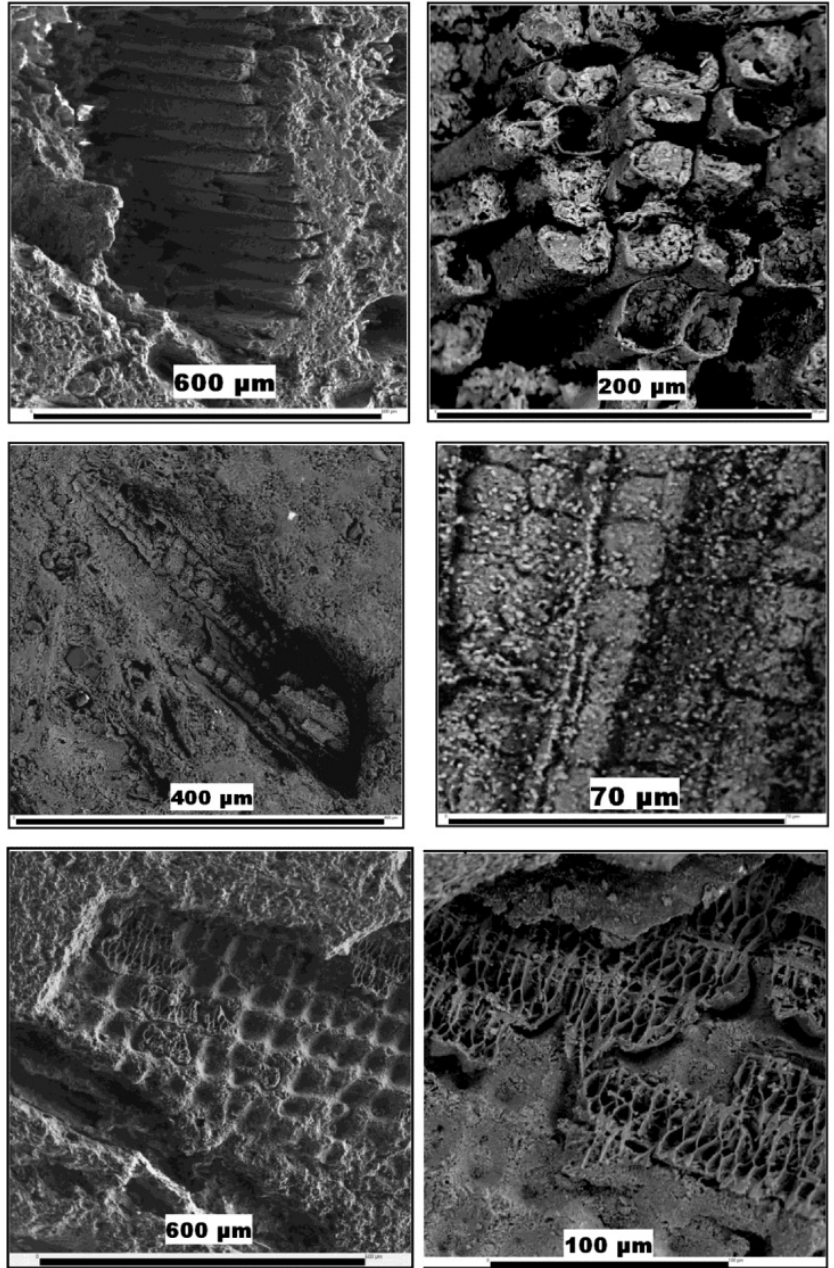

Figure 10. SEM images of VM remnants (top SD, center SSH, bottom $\mathrm{RH}$ ). 
The SD grains preserve the fibers in their raw form, forming empty microtubes. While between the grains and recrystallized clay matrix no voids can be observed, the individual tubes show distinct boundaries on fractured surfaces. Tube diameters vary in the $10-20 \mu \mathrm{m}$ range according to their dimensions in the raw state. SSH grains leave less material behind due to the significant shrinkage by firing. However, the polygonal aspect of remnants still is observed, according to fabric made up by bunches of fibrils observed by OMTPL. The most spectacular remnants are formed by $\mathrm{RH}$ grains, under the form of isolated microporous systems. A thin submicrometric layer is formed by the outer part of grains. In the inside a hollow honeycomb-like structure is revealed. The $\mathrm{SiO}_{2}$ network is made up by the walls of original cells after the organic matter is decomposed. Additionally, characteristic impressions are formed by outer protuberances of the husks. The observations prove that in VM the most well preserved parts are those with higher cation content. Besides importance for archaeometry, these results were found to explain thermal properties of clay bricks in which these materials are used as pore forming additives. Thermal conductivity experiments revealed that SSH produces the highest drop in conductivity, while the smallest effect is observed for SD (Bánhidi et al. 2007, Bánhidi \& Gömze 2008). The trend observed for density and porosity of fired clay bodies with these VM additives is similar: lowest density and highest porosity for mixtures with SSH, then SD and finally RH (Fig 11).
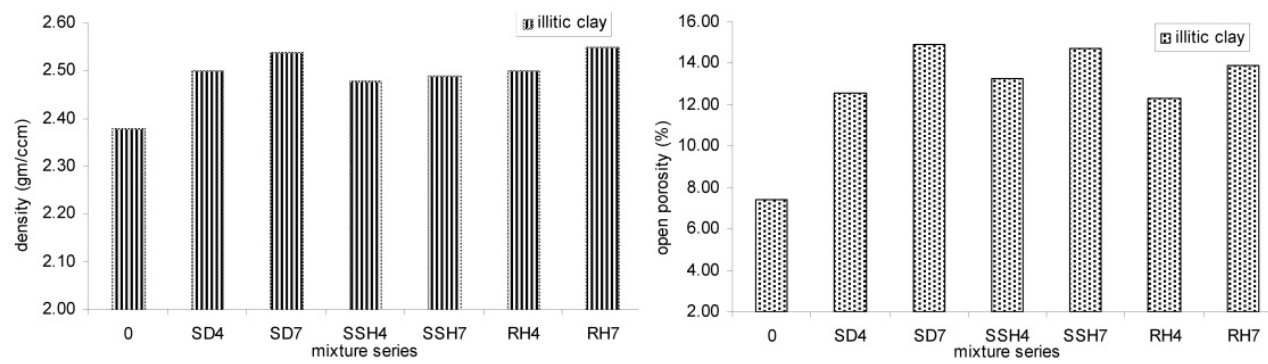

Figure 11. Fired density (left) and open porosity (right) of an illitic clay with VM additives ( $0=$ no additive in clay, $4=4 \mathrm{wt} \%$ additive, $7=7 \mathrm{wt} \%$ additive in clay for raw wet weight)

\section{Formation of fabric replacement and replica structures, application for plant identification in archeological ceramics/plasters}

Fabric replacement and replica structure formation can be modeled based on experimental results, and actual remnants can be deciphered to identify their original plant materials. A classification is needed not only for VM types, but for the different parts of plants. The hardest parts are grains and stems, material covering the grains (hulls, husks, etc.), stalks and leaves. As VM types, we may consider cereals, different wood materials and bean-like crops. Regarding cereals three major parts are often encountered in archaeological materials: grains, husks, stalk (straw) and leaves. In the case of bean-like crops situation is similar. However, wooden materials could be expected less frequent as tempers in ceramics. However, just like grass, they can be either intentionally added or accidentally enclosed in clay masses. 
In archaeology, remnants of plant materials offer data about the lifestyle of extinct cultures. The remnants are mainly referred to as "phytoliths" describing the mineral nature of materials with vegetal origins. Their materials are usually $\mathrm{SiO}_{2}$ or $\mathrm{CaCO}_{3}$ as result of silicification or carbonation. By heat induced transformations the silicification is specific, and in lack of microbeam analysis, cations in the $\mathrm{SiO}_{2}$-glass are often not determined. According to the previous sections of this paper, evidence turned up that inorganic remnants and their chemistry is plant specific. One of the direct applications of these results was in the case of medieval clay bricks (Kristály et al. 2011). The large number of pores was indicative for use of additives (or tempers, in archeological terms) and microscopic remnants were observed. A plant biological investigation of remnants showed that the species was Triticum Monococcum L. a wheat being cropped up to the $12^{\text {th }}$ century, in the region from which samples originates. The historical dating of brick material based on their archeological context was estimated to be from years 1100 A.D. As shown in Fig 12 the characteristic morphology of husks is preserved, down to micrometric precision. One part of remnants is a glassy layer on the clay matrix, another part being the tiny nanoporous husk fibers. Other typical preserved details are found as the grain shells (Fig 13) which may seem as whole wheat grains by the naked eye but on a microscopic scale it is revealed that a shell of the form of grain is filled by the clay material and the shape is then preserved. Notice the thin white glassy film on the border of grain-replica and clay matrix.
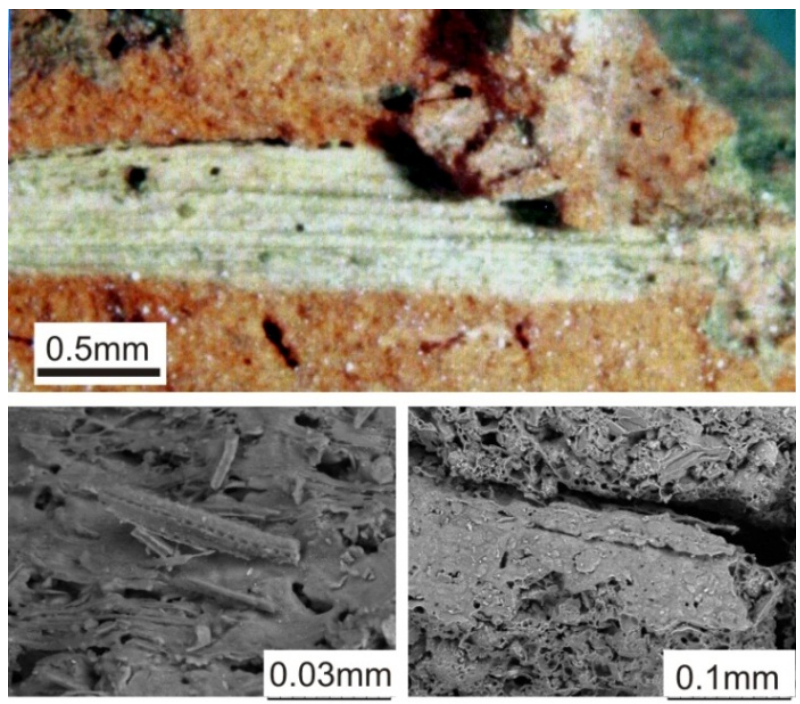

Figure 12. Remnants of T. Monococcum L. husks(upper photo by István Nyilas, BSE images by Péter Pekker)

Phytolith research does not focus only on heat induced remnants, but on all plant remnants indifferent of transformation processes. In all cases, but mainly in ceramic related findings cellulose is the key component for the preservation of shape, morphology and size of the $\mathrm{VM}$ parts in replicas and replacement structures too. 

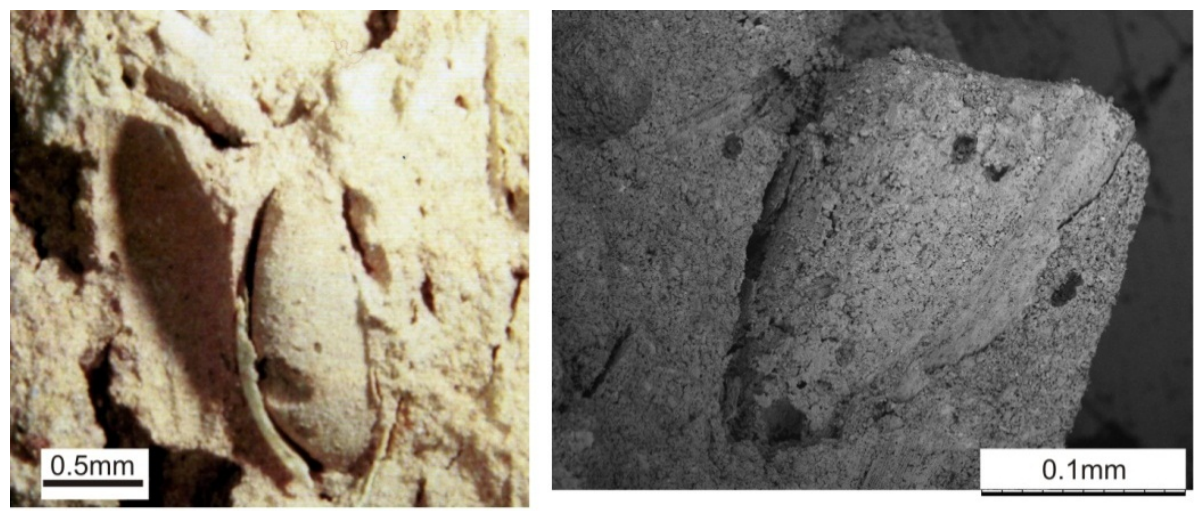

Figure 13. Remnants of T. Monococcum L. grains(left photo by István Nyilas, BSE images by Péter Pekker)

Other plant materials are also frequently recognized based on their remnants and the research field of Phytoarchaeology or Archaeobotany has become basic in archaeological research.

\section{Elastic behavior of cellulose-rich vegetal materials}

Shaping and deformation studies trough vacuum extruded masses of brick clays and vegetal materials showed that plant materials bear specific elasticity (Kristály \& Kocserha 2010). Albeit a direct statistical correlation was not possible between the texture, composition and elasticity of VM samples, specific trends were recognized. First, the expansion of VM-free clay materials was tested to create a realistic baseline for the phenomena. Values $<1 \%$ of the extruded diameter were observed, showing a good evacuation of air during extruding process. The further trends can be summarized as depending both on the quantity of cellulose in VM as the amount of VM in clay mixture but also the mineralogy of raw clays (Fig 14), expressed in muscovite content.

The results were obtained on experimental series of 10 pieces each being measured, for every clay type. In Fig 14 the expansion of four types of clays (LZ=carbonatic, $\mathrm{LS}=$ carbonatic muscovitic, $\mathrm{S}=$ =illite-muscovitic, $\mathrm{K}=\mathrm{illitic}$-muscovitic) is shown with regard to VM type, admixed amount and extruding order for 10 test pieces. Besides the compacting effect of extruder head, the effect of VM and their quantity is evidenced. Comparing Fig 15 to Fig 14 it is clear that the main influence is to be searched in VM composition and DTA peak areas bear the information. An approach to cellulose content was made by relative ranking of DTA exothermal peaks. This way, the smallest amount of cellulose (and similar materials) is found in $\mathrm{RH}$, also observed by the other methods of investigation. SD shows to bear more cellulose and SSH has the highest content. This ranking is also indicative for VM elasticity, since cellulose fibrils directly control it. On the other hand the fabric type observed by microscopy is indicative for the elasticity of VM type: the SD is tubular-fibrous, SSH is sponge-like while RH is hollow, massive. Based on the distribution of structural porosity and chemical elements, $\mathrm{SSH}$ is expected to bear the highest elasticity. 


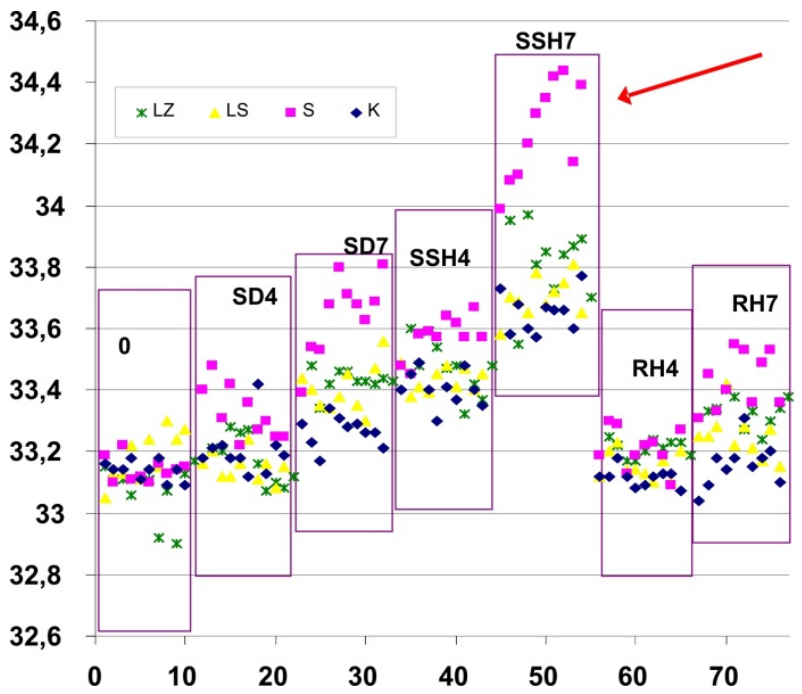

Figure 14. Expansion of different clay types with different VM additives

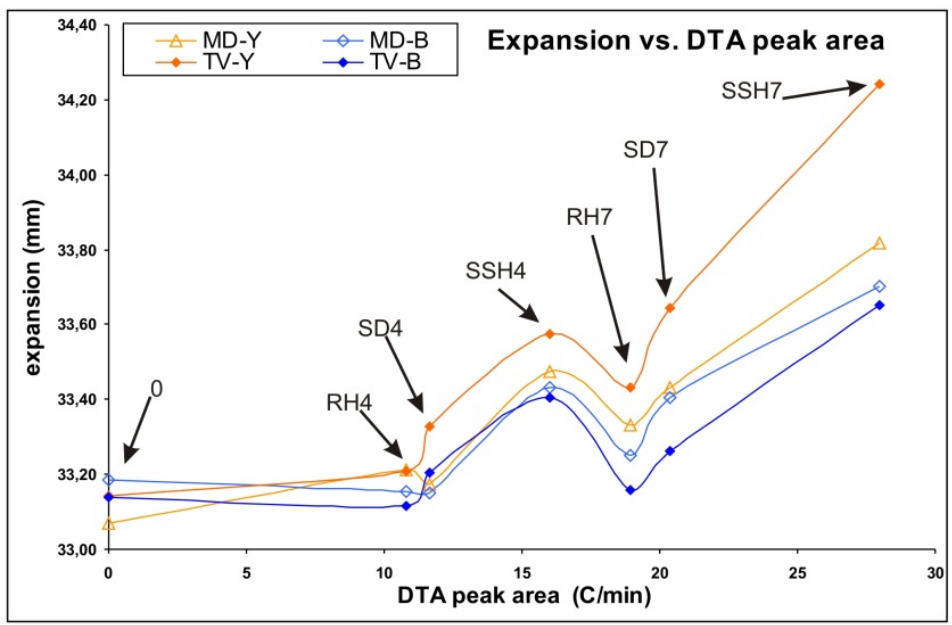

Figure 15. Expansion vs DTA peak area.

\section{Effect of porous cellulose structures and thermal decomposition on clay mineral dehydration and dehydroxylation}

On the TA measurements involving illitic clay with SSH a change in exothermal heat quantity and illite dehydroxylation was observed as compared to the raw clays and SSH material. DTA peaks indicate that heat evolved by cellulose combustion is decreased in the presence of illitic material for SSH containing mixture, while the high temperature $\left(>750^{\circ} \mathrm{C}\right)$ $\mathrm{OH}^{-}$loss of illite-sericite material is decreased in terms of heat absorption. This observation 
was validated by a second set of TA measurements also (Table 4). A reasonable explanation is the nature of SSH fabric, according to term "sponge-like" it has a suction effect over the

\begin{tabular}{lccc}
\hline & SD & SSH & RH \\
raw VM & 55.71 & 68.75 & 31.38 \\
illtic-1 & 53.76 & 34.65 & 55.06 \\
illitic-2 & 42.56 & 38.02 & 42.22 \\
carbonatic-1 & 56.68 & 55.05 & 59.69 \\
carbonatic-2 & 65.42 & 59.01 & 62.18 \\
\hline
\end{tabular}

Table 4. Reation heats of $\mathrm{VM}$ in mixtures $(\mathrm{J} / \mathrm{mg})$

$\mathrm{OH}^{-}$groups becoming instable in mineral structures by rising $\mathrm{T}\left({ }^{\circ} \mathrm{C}\right)$. TG and DTG readings also confirmed that the weight loss in the high temperature illite dehydroxylation is less than expected according to measurements on raw clay and other mixture samples (Fig 16). Background shifts are due to the different porosity before oxidation and to recrystallization in different degree after illite dehydroxylation. XPD on mixtures fired at $700^{\circ} \mathrm{C}$ indicated also that clay mineral relict structures (like smectite anhydrate, chlorite anhydrate) have lesser amount in mixtures with SSH than other VM.

This process could also be responsible for the lowest amorphous material content of fired mixture samples (section 8.).

\section{Effect of the vegetal materials presence on the amorphous material content of fired clay bricks}

Quantitative Rietveld-refinement of XPD on fired clay+VM mixtures indicated that in some cases the interaction of $\mathrm{VM}$ with clay material can lead to the reduction of amorphous content as residual metastable phase at firing (Fig 17).

Firing induces changes are mainly the crystallization of $\mathrm{Ca}$ and $\mathrm{Mg}$ aluminum-silicates and hematite but Rietveld-refinement with internal standard for amorphous content determination also revealed changes less frequently mentioned in literature. Such are crystallization of quartz (denoted Quartz2) and microcline (denoted Microcline max.) or the reduction of amorphous content by the presence of VM materials. The quartz formed during firing is crystallized from the $\mathrm{SiO}_{2}$ liberated on clay minerals recrystallization. Note that its amount is higher in VM mixture samples only for the illitic (TV-B) clay. The composition is the result of transformation illitic material into K-feldspar and with cations from chlorite breakdown into spinel (Fig 18), in lack of $\mathrm{Ca}$ and $\mathrm{Mg}$ for silicate formation. Presence of $\mathrm{H}_{2} \mathrm{O}$ at $<700^{\circ} \mathrm{C}$ from muscovite and sericite dehydration is a catalyzing agent for grain boundary diffusion, a key process for feldspar and other minerals crystallization. Akermanite is formed from the smectitic-chloritic clay minerals. Reduction of amorphous content is accompanied by increase in microcline and quartz2 content, the heat effect of VM during firing, aiding the recrystallization. 


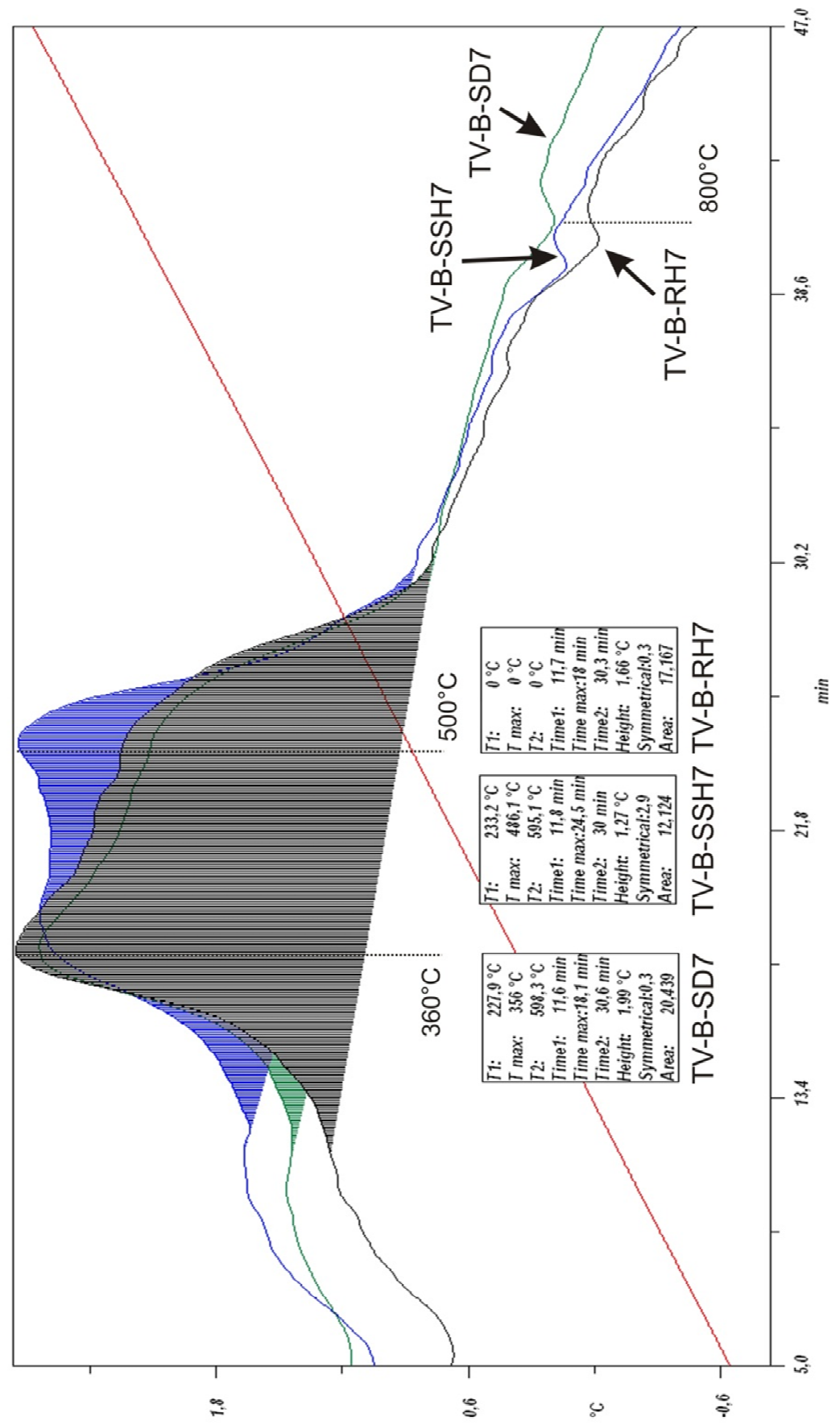

Figure 16. DTA curves for illitic clay (TV-B) with VM additives in $7 \mathrm{wt} \%$ 

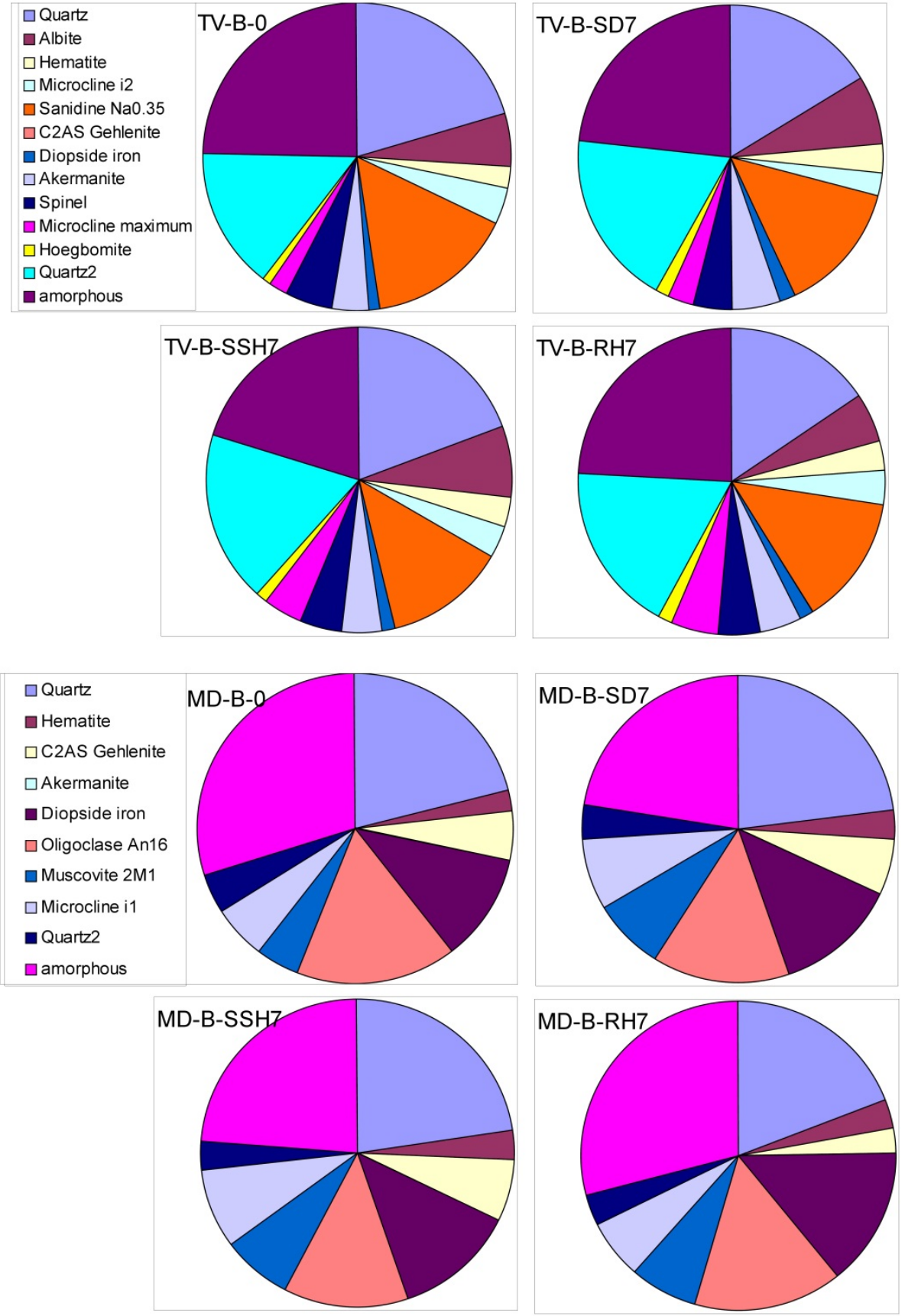

Figure 17. Quantitative mineralogical composition of fired blank and VM containing clays 


\begin{tabular}{|c|c|c|c|c|c|c|c|c|}
\hline & $\begin{array}{l}0 \\
0 \\
p^{\prime} \\
\vec{l}^{\prime}\end{array}$ & 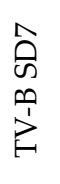 & 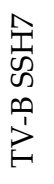 & 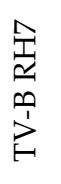 & $\begin{array}{l}\circ \\
\stackrel{\infty}{1} \\
\stackrel{1}{\Sigma}\end{array}$ & $\begin{array}{l}\hat{\hat{O}} \\
\text { के } \\
\text { 尚 } \\
\stackrel{2}{\Sigma}\end{array}$ & 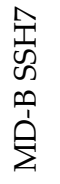 & 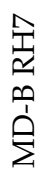 \\
\hline Akermanite & 4 & 5 & 4 & 4 & & & & \\
\hline Albite & 6 & 7 & 7 & 5 & 2 & 3 & 3 & 3 \\
\hline Diopside (Fe) & 1 & 1 & 1 & 1 & 11 & 13 & 12 & 14 \\
\hline Gehlenite & & & & & 5 & 6 & 6 & 3 \\
\hline Hematite & 2 & 3 & 3 & 3 & & & & \\
\hline Hoegbomite & 1 & 1 & 1 & 1 & & & & \\
\hline Microcline & 4 & 3 & 3 & 4 & & & & \\
\hline Microcline (max.) & 2 & 3 & 4 & 5 & 6 & 8 & 8 & 6 \\
\hline Muscovite 2M1 & & & & & 4 & 7 & 7 & 7 \\
\hline Oligoclase (An16) & & & & & 16 & 14 & 13 & 15 \\
\hline Quartz & 21 & 16 & 20 & 15 & 21 & 23 & 23 & 19 \\
\hline Quartz2 & 15 & 19 & 18 & 18 & 4 & 4 & 3 & 3 \\
\hline Sanidine (Na0.35) & 15 & 14 & 13 & 13 & & & & \\
\hline Spinel & 5 & 4 & 4 & 4 & & & & \\
\hline amorphous & 25 & 23 & 20 & 24 & 30 & 22 & 24 & 29 \\
\hline
\end{tabular}

Table 5. Absolute quantitative mineralogical composition of VM bearing fired clay mixtures

$$
\begin{aligned}
& (\mathrm{K}, \mathrm{Na}) \mathrm{Al}_{2} \mathrm{Si}_{3} \mathrm{AlO}_{10} \rightarrow(\mathrm{K}, \mathrm{Na}) \mathrm{AlSi}_{3} \mathrm{O}_{8}+\mathrm{Al}_{2} \mathrm{O}_{3}+\mathrm{H}_{2} \mathrm{O} \\
& \text { amorphous feldspar amorphous? } \begin{array}{l}
\text { from muscovite } \\
\text { dehydroxilation }
\end{array} \\
& \text { "meta-illite" } \\
& \text { reagent }
\end{aligned}
$$

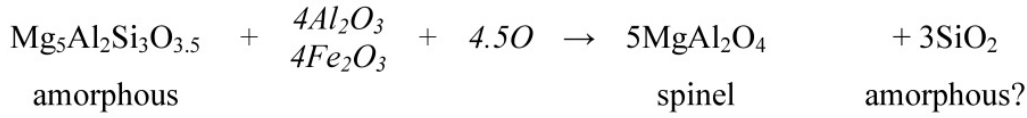

$$
\begin{aligned}
& \text { "meta-chlorite" }
\end{aligned}
$$

Figure 18. Two of the main reactions in illitic clay that determine the fired mineralogy (in the second reaction Fe may replace $\mathrm{Al}$ in spinels) 
In the case of carbonatic clays the reduction of amorphous content is accompanied by increase in gehlenite, diopside and microline content, which were allowed to crystallize in higher amounts by the presence of VM.

\section{Conclusions}

To understand the behavior of VM and their interactions with clay matrix it's useful to approach them as cellulose based engineering materials. From the point of view of mineralogists, VM may not show too large differences as regarding the analytical techniques routinely used for geological materials characterization. The observations made on experiments with VM transformations are also useful in other research fields, like archaeometry, making it easier to recognize VM remnants and identify the original plants. As regards the interaction between vegetal materials and clay minerals, clay based fired products, DTA and XRD have shown that selective thermal interactions and recrystallization may take place.

\section{Author details}

Ferenc Kristály

University of Miskolc, Faculty of Earth Science and Engineering, Miskolc-Egyetemváros, Hungary

\section{Acknowledgement}

Help was provided by Dr. István Kocserha (Univesrity of Miskolc) at the preparation of mixtures and experimental set-up of clay-VM mixture firing. István Papp (Univesity of Debrecen) provided the measurements and helpful discussions on the EGA analysis. Preparation of this paper was supported by the European Union and the European Social Fund under the grant agreement no. TÁ MOP-4.2.1.B-10/2/KONV-2010-0001 in the framework of the New Hungary Development Plan.

\section{References}

Abou-Sekkina, M.M., Issa, R.M., Bastawysi, A.E-D.M. \& El-Helece W.A. (2010) Characterization and Evaluation of Thermodynamic Parameters for Egyptian Heap Fired Rice Straw Ash (RSA). International Journal of Chemistry, Vol. 2/1, pp 81-88

Bánhidi V. \& Gömze A.L. (2008) Improvement of insulation properties of conventional brick products. Materials Science Forum Vol. 589, pp 1-6

Bánhidi V., Gömze L.A. \& Pázmándi P. (2007) Modification of heat conductivity in commercial brick products by recharging bio-waste material additives. MicroCAD 2007., Materials Science and Material Processing Technologies, 1-4, 2007

Das K., Ray D., Bandyopadhyay N. R., Sengupta S. (2010) Study of the Properties of Microcrystalline Cellulose Particles from Different Renewable Resources by XRD, FTIR, Nanoindentation, TGA and SEM. J. Polym. Environ. 18, pp 355-363 
Kristály F. \& Gömze A. L. (2008): Remnants of organic pore-forming additives in conventional clay brick materials: Optical Microscopy and Scanning Electron Microscopy study. Építőanyag, 2008/2, pp. 34-38

Kristály F., Kelemen É., Rózsa P., Nyilas I. \& Papp I. (2011): Mineralogical investigations of medieval brick samples from Békés county (SE Hungary). Archeometry.

Kristály, F. \& Kocserha, I. (2010): Correlations between combustion type additives and expansion after extrusion of clay bricks. Materials Science Forum Vol. 659, pp 43-48

Kristály, F., Gömze, A..L. \& Papp, I. (2010): The transformation of added vegetal waste materials during clay brick firing. Materials Science Forum Vol. 659, pp 37-42

Szöőr Gy. \& Bohátka S. (1985): Derivatograph-QMS system in geochemical research. Thermochimica Acta 92, pp. 395-398

Thygesen A., Oddershede J. , Lilholt H. , Thomsen A. B. \& Stahl K. (2005) On the determination of crystallinity and cellulose content in plant fibers. Cellulose, 12, 563-576

Ververis C., Georghiou K., Christodoulakis N., Santas P. \& Santas R. (2004) Fiber dimensions, lignin and cellulose content of various plant materials and their suitability for paper production. Industrial Crops and Products 19, pp 245-254

Wojdyr, M. (2010) Fityk: a general-purpose peak fitting program. Journal of Applied Crystallography, 43, 1126-1128.

Zhao H., Kwak J. H., Zhang Z. C., Brown H. M., Arey B. W. \& Holladay J. E. (2007) Studying cellulose fiber structure by SEM, XRD, NMR and acid hydrolysis. Carbohydrate Polymers 68, pp 235-241 